\title{
Reaksie op die artikel "'n Ekokrities-filosofiese perspektief op die kortverhaal 'Katvoet' (Riana Scheepers)" deur Carien Smith (Tydskrif vir Geesteswetenskappe 58(2):310-329)
}

\author{
Susan Meyer \\ Fakulteit Opvoedkunde \\ Noordwes-Universiteit \\ Potchefstroomkampus \\ E-pos: Meyer.Susan@nwu.ac.za
}

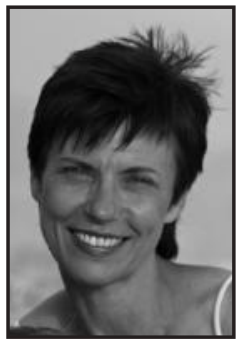

Susan Meyer
SUSAN MEYER is 'n senior lektor in Afrikaans aan die Fakulteit Opvoedkunde, NoordwesUniversiteit, Potchefstroom, en is sy deel van die Navorsingseenheid Tale en Literatuur in SuidAfrikaanse konteks aan die NWU. Sy het in 1990 die graad MA in Afrikaanse letterkunde verwerf aan die Universiteit van Pretoria en in 1993 die DLitt et Phil-graad aan die Universiteit van SuidAfrika. Haar navorsingsbelangstelling lê hoofsaaklik by die ekokritiese benadering tot die eietydse Afrikaanse prosa. Dit is toegespits op die ontwikkeling van die ekokritiese gesprek in SuidAfrika en op die toepassing van internasionale ekokritiese teorieë in die analise van Afrikaanse literêre tekste. Sy bestudeer ook die verskynsel van groen postkolonialisme in Afrikaanse romans, en dus die wyses waarop daar op voortgaande politieke en omgewingsprobleme gereageer word in die Afrikaanse letterkunde.
SuSAN Meyer is a senior lecturer in Afrikaans at the Faculty of Education of North-West University, Potchefstroom, and part of the Research Entity Language and Literature in South African Context at the NWU. She obtained the MA degree in Afrikaans literature at the University of Pretoria in 1990 and the DLitt et Phil degree at the University of South Africa in 1993. Her research involves an ecocritical approach to contemporary Afrikaans literature. It focuses on the development of the ecocritical discourse in South Africa and on applying the most recent international ecocritical theories in analysing Afrikaans literary texts. She also explores the manifestation of green post colonialism, that results from the converging of conservation oriented and postcolonial perspectives, in Afrikaans novels.

Ek reageer graag op Carien Smith se artikel "'n Ekokrities-filosofiese perspektief op die kortverhaal "Katvoet" (Riana Scheepers)" in die Junie-uitgawe.

Die energie van 'n jong navorser in die veld van die ekokritiese teksanalise en -kritiek is baie welkom. Dan is hier ook 'n navorser aan die woord wat met 'n helder formulerings- en argumentasievermoë 'n gewaardeerde nuwe stem in die relatief jong ekokritiese diskoers op die (Suid-)Afrikaanse letterkundeterrein is. 
Wanneer 'n literêre teks deur ' $n$ ander teoretiese lens beskou word as wat vroeër gedoen is, soos wat Carien Smith hier met 'n tweede navorsingsartikel oor Riana Scheepers se verhaal "Katvoet" doen, deel die leser in die opwinding wat Reuben Ellis so goed verwoord: "Approaching and re-approaching texts, figuring out how to read them, has always been a mind-expanding thing."

Die bevindings uit Smith se fenomenologiese bestudering van "Katvoet" is in 2016 in LitNet Akademies gepubliseer. Haar artikel in die vorige uitgawe van die Tydskrif vir Geesteswetenskappe bied 'n ekokrities-filosofiese blik op die verhaal en daar word geput uit die teoretiese raamwerk van beide vakterreine. Die navorser laat blyk dat sy 'n goeie teoretiese greep op die kernbeginsels van die ekokritiek het; formulerings soos "tekste waar ekokritiek teenwoordig is" (p. 320), en "prosawerke met 'n ekokritiese aanslag" (p. 321) lei egter die aandag na die kwessie van terminologie wat die potensiaal het om verwarring te skep. In die lig daarvan dat die ekokritiek'n bepaalde benaderingswyse of ingesteldheid in die bestudering van 'n teks behels, ${ }^{2}$ sou 'n mens versigtig moet wees om te verwys na werke met 'n ekokritiese aard of aanslag. Die benaderingswyse tot die teks kan wel ekokrities wees, met ander woorde die navorser beskou of ondersoek die teks vanuit daardie perspektief.

'n Mens begryp wat bedoel word wanneer Smith van "ekokritiese tekste" (byvoorbeeld p. 319) praat, sy wil verwys na tekste wat 'n natuurgerigte fokus het, met ander woorde die natuur - en moontlik die mens se verhouding daarmee - staan sentraal. 'n Mens begryp ook dat die kern van die probleem hier die behoefte aan'n enkele woord is om te verwys na literêre werke met 'n sterk natuurgerigte aard. Henriëtte Loubser het onlangs die aandag op die term ekoteks gevestig en hierdie term goed belyn in haar PhD-studie waarin die uitbeelding van omgewingskwessies in Afrikaanse kinder- en jeugliteratuur ondersoek word. Sy beskryf ekotekste as "fiksietekste waar daar'n definitiewe aansny van bestaande omgewingsprobleme en -kwessies is", oftewel tekste wat "krities na die mens en sy verhouding tot die niemenslike kyk, [...] wat bewus maak, wat tot die gewete spreek en wat (hopelik) tot optrede aanleiding sal gee" (Loubser 2017:48).

Nog 'n verwante term is nature writing, wat ek in die ekokritiese bestudering van Schalk Schoombie se roman Boomkastele: sprokie vir'n stadsmens probeer vertaal het as natuurgesentreerde skryfwerk (Meyer 2016:1 204). Dit is 'n genre gekenmerk deur die uitbeelding van 'n persoonlike verbintenis met die natuuromgewing en persoonlike interpretasie van die natuur, maar ook deur getrouheid aan analitiese waarneming en (natuur)wetenskaplike feite (BurtonChristie 1993:157). Natuurgesentreerde skryfwerk is dus 'n kombinasie van wetenskaplike verslaggewing en artistieke uitdrukking, 'n poging om met 'n wetenskaplike oog te kyk en met literêre effek te skryf (Lilley 2013, Stephenson 1995:171).

Ons dilemma is dus dat terme soos ekotekste en natuurgesentreerde skryfwerk aan spesifieke kwaliteite of eienskappe gekoppel word, sodat daar fyn getrap moet word in die verwysing na tekste waar die uitbeelding van die natuur nie noodwendig met aandag aan omgewingskundige praktyke of probleme gebeur nie en waar (natuur)wetenskaplike waarneming en feite ook nie

$1 \quad$ Hierdie waardering vir die herbesoek an literêre werke kom uit Ellis se bydrae "Reading New Places in a Time of Change" tot Cheryll Glotfelty se samestelling van terugskouings op die eerste twintig bestaansjare van ASLE (The Association for the Study of Literature and Environment), deur die stigterslede daarvan, in 2013.

2 Lawrence Buell, een van die baanbrekers vir ekokritiek, beskou hierdie dissipline as 'n (vraagstukgedrewe) ondersoekpraktyk, toegespits op die bestudering van die verhouding tussen kunsvorms (onder andere letterkunde) en die omgewing, en onderneem in 'n gesindheid van besorgdheid oor en toewyding aan omgewingskundige praktyke of -gebruike (Buell 2005:11).

Tydskrif vir Geesteswetenskappe, Jaargang 58 No. 3: September 2018

doi.10.17159/2224-7912/2018/v58n3a14 
ter sprake is nie, maar waar die natuur tog 'n groter rol speel as dat dit bloot agtergrond vir die menslike drama bied. Die term natuursentriese teks impliseer weer dat die natuur of natuurkwessies as middelpunt van die uitgebeelde werklikheid aangebied word, wat nie noodwendig die geval is in werke met (ook) 'n sterk fokus op die natuuromgewing nie. Natuurtekste is weer'n baie breë term en kan ook nieliterêre tekstipes insluit wat met die natuur of inligting daaroor gemoeid is. Die veiligste opsie bly tans maar bewoordings soos " $n$ teks met'n sterk natuurteenwoordigheid/natuurgerigtheid" of "'n teks waarin die natuur(omgewing/elemente) om aandag vra".

'n Interdissiplinêre benadering tot'n literêre teks kan 'n verrykende ervaring wees. Dit kan egter probleme oplewer wanneer die teoretiese fundering van bepaalde konsepte gedoen word met aandag aan die perspektiewe wat slegs een van die raamwerke bied. Die probleme word selfs groter wanneer daar in die benutting van hierdie konsepte in die ontleding van 'n teks grootliks na die veld van die ander dissipline beweeg word.

Die konsepte agent, agentskap, en morele agent is een bepaalde "stel konsepte" wat die navorser onderneem om in hierdie studie te benut. Waar'n teoretiese agtergrond vir hierdie konsepte verskaf word (afdeling 3), word dit dan binne konteks van die filosofie en met behulp van filosofieteorieë gedoen, veral van die aksiefilosofie (Philosophy of Action). Die bronne waarop die sterkste gesteun word, is The Oxford Companion to Philosophy, waarin Horn die konsepte agent en agency beskryf, en Stanford Encyclopaedia of Philosophy, waaruit Schlosser asook Schpall en Wilson se insigte oor hierdie begrippe kom.

Die afdeling waar die ontleding van die teks aangepak word (afdeling 7), begin met 'n direkte verwysing na die ekokritiek as perspektief wat die ondersoek rig. Dit is egter duidelik dat, wanneer die terme agent en agentskap in die teksontleding benut word (hoofsaaklik in afdeling 7.3), daar met geen verdere betekenisimplikasies van hierdie woorde gewerk word as dié wat binne die terrein van die filosofie daaraan gekoppel is nie - en wat behels dat 'n agent "'n wese (is) wat die vermoë of kapasiteit het om te kan optree", en agentskap "die beoefening van hierdie vermoë" (Horn, Thompson en Schlosser, soos aangehaal deur Smith op p. 315). Na die konnotasies wat aan die terme agency en agentic power geheg word binne die denkraamwerk van die nuwe materialisme, en na die wyse waarop die materiële ekokritiek deur die idees van die nuwe materialisme gevoed word, word nie verwys nie.

Die betekenisskakerings wat Barad (2003:822), Alaimo en Hekman (2008:7), Bennet (2010:xvi) asook Iovino en Oppermann (2012:79) aan hierdie terme toevoeg, binne die denkraamwerk van die nuwe materialisme, sou'n verrykende dimensie kon verleen aan Smith se teoretiese verrekening van hierdie konsepte en waarskynlik ook aan die teksontleding. Hoe die konsep "agency" met die groter kwessie van materialiteit skakel, is 'n belangrike aspek wat moontlik beter benut sou kon word in die ontrafeling van die teks.

Die agtergrond wat hier belangrik is, is die "material turn" (oftewel die ommekeer in die guns van materialiteit) as reaksie op die sogenaamde "linguistic turn". ${ }^{3}$ Die neiging in die postmoderne en poststrukturalistiese denke om die wêreld te dematerialiseer tot linguistiese en sosiale konstruksies het daartoe gelei dat die materialiteit van die mens en die omringende wêreld feitlik geïgnoreer is; die nuwe materialisme wil weer aandag gee aan die fisiese

In die literatuurteorie word die "linguistic turn" geassosieer met die postmoderne teorieë van poststrukturalisme en dekonstruksie wat die literêre toneel die afgelope dekades oorheers en bykans onaantasbaar geword het, en waarin 'n abstrakte tekstuele siening van die werklikheid vooropgestel is (Barad 2003:801). Teoretici wat fokus op die krag van taal om die realiteit te skep, eerder as dat taal beskou word as 'n refleksie van die werklikheid, is onder andere Julia Kristeva en Michel Foucault. 
materialiteit van die werklikheid. Iovino en Oppermann (2012:76) verwoord dit as "focus(ing) attention on bodily experiences and bodily practices, where 'body' refers not only to the human body but to the concrete entanglements of plural 'natures', in both human and more-thanhuman realms".

Dus word 'n terugkeer bepleit na 'n teorie waarin die belangrikheid van die materieel tasbare werklikheid, wat interaktief inwerk op beide die menslike en die niemenslike wêreld, erken word. Hoewel daar in Smith se artikel deur middel van die opskrif "Ekokritiek en die nuwe materialisme" (afdeling 6) iets plaasvind in die lyn van erkenning aan die belangrike plek wat die laasgenoemde teorieë die afgelope jare in die ekokritiese bestudering van literêre tekste begin inneem het, word daar slegs in die laaste paragraaf van hierdie afdeling, en kortliks, by die nuwe materialisme uitgekom. Die sleutelterm, materialiteit, sou op vollediger wyse beskryf kon word as slegs met verwysing na materiële formasies waarin die "samehang en vervlegting van niemenslike sowel as menslike liggame" geïmpliseer word. Ander definiërende beginsels betreffende materie, onder andere dat die tradisioneel nielewende oor kragte van interaksie en beïnvloeding beskik - ook ten opsigte van die mens - en omtrent die mens as deel van 'n interaktiewe geheel van materialiteit, sou erken kon word en moontlik met vrug benut kon word in die analise van "Katvoet".

Stellings soos dat "die natuur in ekokritiek uitgebeeld word as 'n mag, of fors, met agentskap" (p. 318) vind ongelukkig plaas sonder verheldering wat betref die belangrike nuanses in die betekenis van "agentskap" binne die spesifieke konteks van die nuwe materialisme. 'n Probleem wat hiermee saamhang, is die direkte oorname van die terme "agent" en "agentskap", sonder verrekening van die breër betekeniskonteks wat deur die teorie van hierdie beweging gebied sou kon word. ${ }^{4}$ Hoewel dit nie maklik is om 'n enkele woord ter vertaling van "agency" te vind nie, sou die begrip vertaal kon word met 'n beskrywende frase, soos "mag van beïnvloeding", om aan die groter teoretiese prentjie en aan die kwessie van die interaktiewe inwerking van materie op die gedeelde sfeer van die menslike en die niemenslike reg te laat geskied.

'n Mens vermoed dat, sonder die benutting van genoemde teoretiese insigte, die potensiaal van die teks ten opsigte van die skep van 'n bewustheid van en 'n sin van skakeling met die materiële wêreld, nie ten volle begryp kan word nie. In watter mate 'n verskralende effek dalk ontstaan het ten opsigte van die insigte wat uit die verhaal geput is, en of dit wel die geval was, kan uiteraard nie met sekerheid gesê word nie.

In die geheel beoordeel, doen Smith se artikel verslag oor besonder verdienstelike navorsing. Argumente wat sterk en oortuigend uitgebou word in die bespreking van die verhaal is eerstens dié omtrent die wyse(s) waarop die algemene filosofiese idees van die Westerse wêreld in die verhaal uitgedaag word, veral die geloof in die basiese binêre opposisies - mens en dier, mind en liggaam, kultuur en natuur - en die ontologiese onderskeid tussen die menslike en die niemenslike. Tweedens word die opheffing van onderdrukkende en dominerende konseptuele raamwerke in "Katvoet" oortuigend beredeneer. 'n Skerpsinnige ontleding van die verhaal ten opsigte van beide hierdie kwessies lei tot die konseptualisering van 'n tipe "alterverhaal" waarvan die doel is om antroposentriese denkwyses met alternatiewe perspektiewe te vervang.

Die alternatiewe perspektiewe wat in "Katvoet" aangebied word, word noulettend onder-

$4 \quad$ Shamiega Chaudhari het ook onlangs die konsep agentskap benut in die artikel "Stilte en agentskap in die slaweroman Philida van André P. Brink", en ook van Schlosser se definisie in die Stanford Encyclopedia of Philosophy gebruik gemaak - "agentskap dui op die uitoefening van die kapasiteit om op te tree" (Chaudhari 2017) - maar Chaudhari se benadering tot Brink se roman bevat geen ekokritiese element nie. 
soek en verrassende bevindings vloei hieruit. In hierdie verhaal word nie slegs gefokus op die antroposentriese sosiale konstruksie van menslike taal nie; die vrou maak op veel meer as haar gehoor staat en haar ingesteldheid op wyer sintuiglike waarnemings en kommunikasie dra by tot haar belewing van die natuur as 'n interaktiewe teenwoordigheid. Die vrou se aksies, liggaamlikheid en sintuiglike vermoëns verander met verloop van die verhaal; sy verdierlik. Deur hierdie proses van verdierliking beleef die vrou 'n kragtige alternatief ten opsigte van die konvensionele subjek-objek-verhouding. Haar interaksie met haar man word in sekere tonele uitgebeeld as 'n vorm van interaksie tussen 'n dierlike self en 'n mens; die "dier" wat sy word, is eerder ervarende subjek as objek.

Om as ekokritikus met die Afrikaanse letterkunde besig te wees, behels die uitdagende werk van eksperimentering met en toepassing van ekokritiese beginsels in 'n veld waar hierdie praktyk betreklik nuut is. Dit is nietemin bevredigende werk; die bestudering van tekste vanuit ekokritiese oogpunt is uiteraard 'n belangrike manier om begrippe en idees in die sfeer van die ekokritiek te verfyn. Dus lê die betekenis van 'n studie soos dié van Carien Smith nie slegs in die benutting van sekere teoretiese idees om 'n bepaalde teks beter te verstaan nie, maar in die poging om tot' $n$ beter begrip van daardie teoretiese idees te kom.

Elke dapper bydrae is waardevol; Carien Smith se toetrede tot hierdie veld verdien applous.

\section{BIBLIOGRAFIE}

Alaimo, S. \& Hekman, S. 2008. Introduction: Emerging models of materiality in feminist theory. In Alaimo \& Hekman (reds.). Material Feminisms. Bloomington \& Indianapolis: Indiana University Press.

Barad, K. 2003. Post humanist performativity: Toward an understanding of how matter comes to matter. Signs. Journal of Women in Culture and Society, 28(3):801-31.

Bennett. J. 2010. Vibrant Matter: A Political Ecology of Things. Durham: Duke University Press.

Buell, L. 2005. The Future of Environmental Criticism: Environmental Crisis and Literary Imagination. Oxford: Blackwell Publishers.

Burton-Christie, D. 1993. 'A feeling for the natural world': spirituality and contemporary nature writing. Continuum, 2(2-3):154-180.

Chaudhari, S. 2017. Stilte en agentskap in die slaweroman Philida van André P. Brink. LitNet Akademies 14(3). https://www.litnet.co.za/stilte-en-agentskap-die-slaweroman-philida-van-andre-p-brink/ Datum van toegang 23 Junie 2018.

Iovino, S. \& Opperman, S. 2012. Material Ecocriticism: Materiality, Agency, and Models of Narrativity. Ecozon@, 3(1):75-91.

Glotfelty, Cherryl. 2013. Literature and Environment, the Long View: Thoughts from the Founders of ASLE. Journal of Ecocriticism 5(1):1-19.

Lilley, D. 2013. Recovering Nostalgia in Nature Writing. Alluvium, https://www.alluvium-journal. org/2013/05/13/recovering-nostalgia-in-nature-writing/ Datum van toegang 23 Junie 2018.

Meyer, Susan. 2016. Natuurgesentreerde skryfwerk as ekosisteem: 'n ondersoek na Boomkastele: 'n sprokie vir 'n stadsmens (Schalk Schoombie). Deel 1. Tydskrif vir Geesteswetenskappe 56(4-2):1 200-1 212, Desember.

Loubser, H. 2017. Die uitbeelding van omgewingskwessies in Afrikaanse kinder- en jeugliteratuur: 'n ekokritiese perspektief. PhD-proefskrif. Stellenbosch: Universiteit van Stellenbosch.

Smith, C. 2018. "'n Ekokrities-filosofiese perspektief op die kortverhaal 'Katvoet' (Riana Scheepers)". Tydskrif vir Geesteswetenskappe, 58(2):310-329.

Stephenson, W.C. 1995. A new type of nature writing? The Midwest Quarterly, 36(2):170-177. 